Paper Number:

DOE/METC/C-97/7274

Title:

Manganese-Based Sorbents for Coal Gas Desulfurization

Authors:

L.D. Gasper-Galvin (METC)

E.P. Fisher (METC)

W.J. Goyette (Chemtals)

Conference:

Advanced Coal-Fired Power Systems '96 Review Meeting

Conference Location:

Morgantown, West Virginia

Conference Dates:

July 16-18, 1996 


\section{Disclaimer}

This report was prepared as an account of work sponsored by an agency of the United States Government. Neither the United States Government nor any agency thereof, nor any of their employees, makes any warranty, express or implied, or assumes any legal liability or responsibility for the accuracy, completeness, or usefulness of any information, apparatus, product, or process disclosed, or represents that its use would not infringe privately owned rights. Reference herein to any specific commercial product, process, or service by trade name, trademark, manufacturer, or otherwise does not necessarily constitute or imply its endorsement, recommendation, or favoring by the United States Government or any agency thereof. The views and opinions of authors expressed herein do not necessarily state or reflect those of the United States Government or any agency thereof. 


\title{
Manganese-Based Sorbents for Coal Gas Desulfurization
}

\author{
Lee D. Gasper-Galvin (LGASPE@ METC.DOE.GOV; 304-285-4832) \\ Edward P. Fisher (EFISHE@METC.DOE.GOV; 304-285-4011) \\ Morgantown Energy Technology Center
}

\author{
William J. Goyette (410-789-8800, x167) \\ Chemetals
}

\section{Introduction}

Manganese-based sorbents have previously been investigated for sulfur removal from coal gases at high temperatures, e.g., $800{ }^{\circ} \mathrm{C}\left(1,472{ }^{\circ} \mathrm{F}\right)$ and above, and with simulated low-Btu fuel gas or mixtures of $\mathrm{H}_{2} \mathrm{~S}$ and $\mathrm{H}_{2}$ in $\mathrm{N}_{2}$ (Turkdogan and Olsson, 1978; Hepworth and Slimane, 1994). The special emphasis on higher temperatures was because manganese oxide is one of the few metal oxides that have stability and coal gas desulfurization potential at such temperatures.

Some studies have been performed at lower temperatures, e.g., 400 to $800{ }^{\circ} \mathrm{C}(752$ to $1,472{ }^{\circ} \mathrm{F}$ ) (Wakker and Gerritsen, 1990a, 1990b); these researchers showed that increasing $\mathrm{H}_{2}$ and $\mathrm{CO}$ increases the sulfur capacity of a sorbent containing Mn oxide and alumina, while increasing $\mathrm{H}_{2} \mathrm{O}$ decreases the sulfur capacity. Thermodynamic studies (Westmoreland, et al. 1976) suggest that Mn-based sorbents may perform much better in the range of 400 to $800{ }^{\circ} \mathrm{C}$ (752 to $1,472{ }^{\circ} \mathrm{F}$ ) than at higher temperatures. Hepworth and Slimane (1994) also showed a graph of calculated equilibrium levels of $\mathrm{H}_{2} \mathrm{~S}$ in the presence of temperatures from 700 to $1,200{ }^{\circ} \mathrm{C}\left(1,292\right.$ to $\left.2,192{ }^{\circ} \mathrm{F}\right)$ for different types of coal gas. The graph indicated that the lowest equilibrium $\mathrm{H}_{2} \mathrm{~S}$ levels were obtained in the presence of oxygen-blown Shell gas at the lowest temperatures. Thermogravimetric analysis studies by Westmoreland, et al. (1977) showed that among sorbents consisting of the oxides of $\mathrm{Mn}, \mathrm{V}, \mathrm{Ca}$, and $\mathrm{Zn}$, the $\mathrm{Mn}$ oxide showed the highest reaction rate over the temperature range 300 to $800{ }^{\circ} \mathrm{C}\left(572\right.$ to $\left.1,472{ }^{\circ} \mathrm{F}\right)$.

Since overall sorbent performance is a combination of the effects of thermodynamics, kinetics, and gas-solid mass transfer resistance, it seems reasonable from the information cited above that an Mn-based sorbent would perform very well in a highly reducing Shell gas at lower temperatures. The present study shows the effect of temperature, inlet $\mathrm{H}_{2} \mathrm{~S}$ concentration, and type of coal gas (air-blown KRW gas versus oxygen-blown Shell gas) on the performance of Mn-based sorbent. The sorbent used for these studies was CST-939 from Chemetals (Baltimore, Maryland). The CST-939 is a proprietary sorbent containing essentially 96 percent $\mathrm{MnO}$, and has previously been marketed as guard bed material for use downstream from hydrodesulfurization units and upstream from reformers in petrochemical refining. 


\section{Objectives}

The intent of this study is to perform a preliminary screening on a particular Mn-based sorbent, CST-939 (from Chemetals), for hot gas desulfurization. The purpose of the preliminary screening is to determine which temperature and type of coal gas this sorbent demonstrates the greatest capacity and efficiency for sulfur removal.

\section{Approach}

The first two sets of experiments, tests CST1 and CST2, were conducted with simulated KRW gas containing 2,000 ppmv $\mathrm{H}_{2} \mathrm{~S}$ and 871 and $343{ }^{\circ} \mathrm{C}\left(1,600\right.$ and $\left.650{ }^{\circ} \mathrm{F}\right)$, respectively. Due to the tremendous capacity of the sorbent, these experiments required as long as 75 hours to achieve breakthrough (breakthrough is defined as $200 \mathrm{ppmv}_{2} \mathrm{~S}$ in the outlet gas). Therefore, the later experiments were conducted with simulated KRW gas (or Shell gas) containing $30,000 \mathrm{ppmv} \mathrm{H}_{2} \mathrm{~S}$ to decrease the time required for breakthrough. A set of six experiments, three with KRW gas and three with Shall gas, were conducted for 1.5 cycles each at temperatures of 343,538 , and $871{ }^{\circ} \mathrm{C}\left(650,1,000\right.$, and $\left.1,600{ }^{\circ} \mathrm{F}\right)$. A fresh sample of the sorbent was used for each set of experiments.

During one of the early experiments (test CST2) using 2,000 ppmv $\mathrm{H}_{2} \mathrm{~S}$, the regeneration temperature was ramped from $343{ }^{\circ} \mathrm{C}\left(650{ }^{\circ} \mathrm{F}\right)$ to $871{ }^{\circ} \mathrm{C}\left(1,600{ }^{\circ} \mathrm{F}\right)$ to determine the lowest temperature that may be sufficient for regeneration with 50 mol percent air/50 mol percent steam. The extent of regeneration was indicated by the amount of $\mathrm{SO}_{2}$ given off at each temperature. Sulfur dioxide as high as 3.0 volume percent was given off after $1 / 2$ hour on-stream at $343{ }^{\circ} \mathrm{C}\left(650^{\circ} \mathrm{F}\right)$, as shown by gas chromatographic analysis, but the concentration then dropped off rapidly and regeneration was not sustained at this temperature. A relatively small amount of $\mathrm{SO}_{2}$ was released at $538{ }^{\circ} \mathrm{C}\left(1,000{ }^{\circ} \mathrm{F}\right)$. The rate of regeneration finally increased at $649{ }^{\circ} \mathrm{C}\left(1,200{ }^{\circ} \mathrm{F}\right)$, at which temperature concentrations as high as 23.8 percent by volume $\mathrm{SO}_{2}$ were measured. The additional $\mathrm{SO}_{2}$ that was released at $760{ }^{\circ} \mathrm{C}\left(1,400{ }^{\circ} \mathrm{F}\right)$ was minimal. Finally, when the sorbent bed was raised to a temperature of $871{ }^{\circ} \mathrm{C}\left(1,600{ }^{\circ} \mathrm{F}\right)$, significant quantities of $\mathrm{SO}_{2}$ were released, giving a concentration as high as 2.2 percent by volume. Since $\mathrm{MnSO}_{4}$ decomposes in air at an atmospheric pressure of $850{ }^{\circ} \mathrm{C}\left(1,562{ }^{\circ} \mathrm{F}\right)$, it is not surprising that additional sulfur was released after heating the sorbent to $871{ }^{\circ} \mathrm{C}\left(1,600{ }^{\circ} \mathrm{F}\right)$. It was concluded that $871{ }^{\circ} \mathrm{C}\left(1,600{ }^{\circ} \mathrm{F}\right)$ would be the best temperature for air-steam regeneration of the sorbent.

During the second sulfidation of the CST2 series of experiments described above, it was noted that a significant amount of $\mathrm{SO}_{2}$ was released during the first hour on-stream. This indicated that regeneration was not complete, even after using the air-steam mixture at $871{ }^{\circ} \mathrm{C}$ $\left(1,600^{\circ} \mathrm{F}\right)$. Another set of experiments (CST3) was conducted in which the first regeneration was conducted with air-steam at $871{ }^{\circ} \mathrm{C}\left(1,600{ }^{\circ} \mathrm{F}\right)$ and the second regeneration was performed in the same manner, except the oxidative regeneration step was followed by a reductive regeneration step. Reductive regeneration was carried out with simulated KRW gas without $\mathrm{H}_{2} \mathrm{~S}$ for 11 hours. The result of the reductive regeneration was that no $\mathrm{SO}_{2}$ was detected during the first 2-1/2 hours on-stream and no higher than $3.0 \mathrm{ppmv}$ was detected afterward. 
Thus, it could be seen that a reductive regeneration step was helpful. For the remaining experiments, a simplified reductive regeneration was used, as described in the Experimental Methods section.

\section{Experimental Methods}

A schematic diagram of the experimental apparatus is shown in Figure 1. The apparatus consisted of a gas-mixing system, a fixed-bed reactor, a water-cooled condenser with a water knock-out pot, an ice water-cooled condenser with a water knock-out pot, a gas sampling system, and a tail-gas cleanup system. The gas mixture feed to the reactor simulated the partially quenched exit gas of an air-blown KRW fluidized-bed coal gasifier or an oxygenblown Shell entrained-bed coal gasifier, with the molar compositions given in Table 1. Gases were supplied from gas cylinders and the flow rates were controlled and monitored through MKS Model 1159B mass flow controllers with two MKS Model 247C four-channel digital readouts, except for the nitrogen purge gas, which was metered through a Matheson Model FM-1050-VIA, 603 tube rotameter. After the gases were mixed in a manifold, they were fed into the fixed-bed reactor. Steam was introduced by feeding a predetermined amount of water into the gas stream via an ISCO Model 100D metering pump.

\section{One-Inch Sorbent Screening Unit}

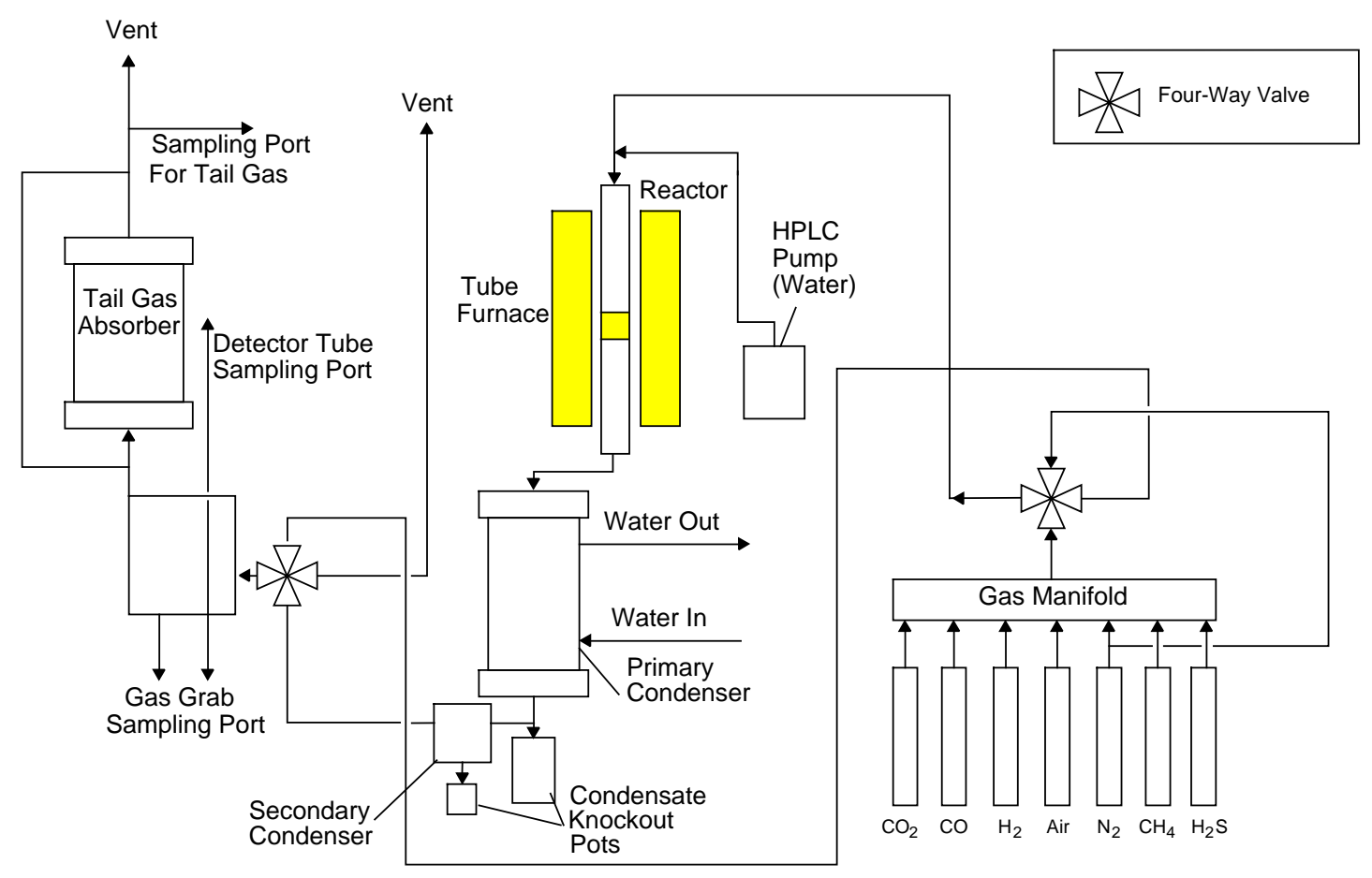

M96001422W

Figure 1 
Table 1. Simulated Gas Composition

\begin{tabular}{|lrlr|}
\hline \multicolumn{2}{|c}{ Shell Gas Percent } & \multicolumn{2}{c|}{ KRW Gas Percent } \\
\hline Carbon Dioxide & 2.0 & Carbon Dioxide & 11.0 \\
Carbon Monoxide & 64.1 & Carbon Monoxide & 12.5 \\
Hydrogen Sulfide & 3.0 & Hydrogen Sulfide & 3.0 \\
Methane & 0.0 & Methane & 1.0 \\
Hydrogen & 27.3 & Hydrogen & 13.8 \\
Steam & 2.0 & Steam & 19.0 \\
Nitrogen & Balance & Nitrogen & Balance \\
\hline
\end{tabular}

The reactor consisted of an alonized 316-stainless steel (SS) tube, with a 2.54-cm (1-inch) outside diameter (OD), a $0.165-\mathrm{cm}(0.065$-inch) wall thickness, and 114.3-cm (45-inch) length. Alonization of the reactor was necessary to minimize the corrosion of the stainless steel by $\mathrm{H}_{2} \mathrm{~S}$, particularly in the presence of high-temperature steam. The reactor was placed vertically in a Lindberg tubular electric furnace.

The gas mixture was preheated as it passed through the top half of the reactor tube. The temperatures of the gas at the inlet and the center of the reactor bed were measured by Omega K-type quick-connect thermocouples located along the central axis. The thermocouples were connected to an Omega Model 199A digital readout via an Omega Model OSW3-20-PG rotary selector switch. The reactor inlet and outlet pressures were measured with Matheson Model 63-5651 $308 \mathrm{kPa}$ (30 psig) test gauges. The reactor was designed to withstand a pressure of $308 \mathrm{kPa}(30 \mathrm{psig})$ and a temperature of $982{ }^{\circ} \mathrm{C}\left(1,800{ }^{\circ} \mathrm{F}\right)$. The overtemperature circuit on the tube furnace was set for $927{ }^{\circ} \mathrm{C}\left(1,700{ }^{\circ} \mathrm{F}\right)$.

The sorbent sample was placed in the center of the reactor and the bed height was $7.6 \mathrm{~cm}$ (3 inches). The sorbent bed was supported on an alonized, 316 SS perforated plate with a layer of glass wool to catch any fines that might be produced from the bed. The gas lines between the reactor outlet and the condenser inlet were heated via Thermolyne heavy Samoxinsulated heating tapes regulated with Omega 6200 temperature controllers and were insulated with a Fiberfax blanket to prevent steam condensation in the gas lines. The exit gas from the reactor was filtered with a Balston Model B49 filter unit containing a Balston Model 05011-BQ filter tube, cooled in two condensers (a primary condenser that was water-cooled, followed by a secondary condenser that was ice water-cooled), and sampled for gas analysis. The tail gas was sent through an absorber (316 SS, 8.9-cm [3.5-inch] OD, schedule 40 pipe, $41.9 \mathrm{~cm}$ [16.5 inches] long) containing a zinc-based sorbent to remove the sulfurous gases before discharge to the atmosphere. The condensates from the two condensers were caught in their respective water knock-out pots located below the condensers. The water knock-out pots consisted of $1.3-\mathrm{cm}(0.5$-inch) OD, 0.089-cm (0.035-inch) wall, 25.4-cm (10-inch) long 316 SS tubes. 
The conditions for oxidative regeneration and reductive regeneration are shown in Table 2. The test matrix, with actual run numbers, sulfidation conditions, and the number of sulfidation/regeneration cycles, is given in Table 3. Gastec precision gas detector tubes were used to determine the $\mathrm{H}_{2} \mathrm{~S}$ and $\mathrm{SO}_{2}$ concentrations in the inlet and outlet gas streams to plus or minus 25 percent. All gaseous components (other than water vapor) were analyzed by gas chromatography of gas grab samples and/or via an on-line VG Prima 600 mass spectrometer. Sulfidation was stopped when the hydrogen sulfide concentration of the effluent gas reached 1,000 ppmv for sulfidations run with KRW gas and $400 \mathrm{ppmv}$ for sulfidations run with Shell gas. Following sulfidation, the reactor was purged with nitrogen to flush out the reducing gas. The oxidative regeneration with air-steam was stopped when the $\mathrm{SO}_{2}$ concentration of the effluent gas was below 50 ppmv. Reductive regeneration was conducted for 4 hours unless the combination of ppmv $\mathrm{H}_{2} \mathrm{~S}$ plus ppmv $\mathrm{SO}_{2}$ dropped below 50 ppmv prior to 4 hours on-stream, at which time the regeneration was stopped. A fresh load of sorbent was subjected to each set of sulfidation/regeneration conditions to establish its sulfur sorption capacity and efficiency. Some experiments were repeated to verify the results, particularly for cases in which any operating difficulties were encountered.

Table 2. Regeneration Conditions

\begin{tabular}{|lrlr|}
\hline \multicolumn{2}{c}{ Oxidative } & \multicolumn{2}{c|}{ Reductive } \\
\hline Temperature & $1,600{ }^{\circ} \mathrm{F}$ & Temperature & $1,600{ }^{\circ} \mathrm{F}$ \\
Pressure & $15 \mathrm{psig}$ & Pressure & $15 \mathrm{psig}$ \\
Composition: & & Composition: & \\
Air & $50 \%$ & Hydrogen & $25 \%$ \\
Steam & $50 \%$ & Nitrogen & $75 \%$ \\
\hline
\end{tabular}

Table 3. Sorbent Test Matrix

\begin{tabular}{|ccc|}
\hline & $\begin{array}{c}\text { Coal Gas/ } \mathrm{H}_{2} \mathrm{~S} \\
\text { Concentration }\end{array}$ & Temperature/Cycles \\
\hline Test Number & $\mathrm{KRW} / 0.2 \%$ & $871^{\circ} \mathrm{C} / 1.5$ \\
CST2 & $\mathrm{KRW} / 0.2 \%$ & $343{ }^{\circ} \mathrm{C} / 1.5$ \\
CST3 & $\mathrm{KRW} / 3.0 \%$ & $871^{\circ} \mathrm{C} / 2.5$ \\
CST4 & $\mathrm{KRW} / 3.0 \%$ & $871^{\circ} \mathrm{C} / 1.5$ \\
CST5 & $\mathrm{KRW} / 3.0 \%$ & $538^{\circ} \mathrm{C} / 1.5$ \\
CST6 & Shell/3.0\% & $343{ }^{\circ} \mathrm{C} / 1.0$ \\
CST7 & Shell/3.0\% & $538{ }^{\circ} \mathrm{C} / 1.5$ \\
CST8 & Shell/3.0\% & $871{ }^{\circ} \mathrm{C} / 1.5$ \\
CST9 & Shell/3.0\% & $343{ }^{\circ} \mathrm{C} / 1.5$ \\
CST10 & $\mathrm{KRW} / 3.0 \%$ & $343{ }^{\circ} \mathrm{C} / 1.5$ \\
CST11 & Shell/3.0\% & $871{ }^{\circ} \mathrm{C} / 1.5$ \\
\hline
\end{tabular}

Sorbent samples were analyzed for total sulfur content and crush strength. Sulfur content was determined using a LECO analyzer. Crush strengths were obtained by compressing the 
sorbent extrudates between the two flat surfaces of a Chatillon crush strength tester until the point of breakage.

\section{Results and Discussion}

Selected $\mathrm{H}_{2} \mathrm{~S}$ breakthrough curves are shown in Figures 2 through 5. These graphs show the effect of temperature in simulated KRW gas, inlet $\mathrm{H}_{2} \mathrm{~S}$ concentration in simulated $\mathrm{KRW}$ gas, type of simulated gas mixture (i.e., KRW or Shell gas), and the effect of temperature in simulated Shell gas, respectively. Each of these graphs will be discussed in more detail below. The data shown are the result of detector tube or mass spectrometer analysis of the outlet $\mathrm{H}_{2} \mathrm{~S}$ concentration.

The $\mathrm{H}_{2} \mathrm{~S}$ breakthrough curves from test series CST1 and CST2, shown in Figure 2, illustrates the dramatic effect of temperature on sulfur removal efficiency and capacity. These tests were conducted with simulated KRW gas containing $2,000 \mathrm{ppmv}$ of $\mathrm{H}_{2} \mathrm{~S}$, at $871{ }^{\circ} \mathrm{C}$ $\left(1,600{ }^{\circ} \mathrm{F}\right)$, and $343{ }^{\circ} \mathrm{C}\left(650{ }^{\circ} \mathrm{F}\right)$, respectively. The final letter of each test number indicates whether it was a first or second sulfidation, e.g., CST1A was the first sulfidation of test series CST1, while CST1C was the second sulfidation of the same test series (CST1B, which is not shown, was the first regeneration). It is apparent from Figure 2 that the CST-939 sorbent performed poorly at $871^{\circ} \mathrm{C}\left(1,600{ }^{\circ} \mathrm{F}\right)$ in the presence of simulated $\mathrm{KRW}$ gas. However, at $343{ }^{\circ} \mathrm{C}\left(650{ }^{\circ} \mathrm{F}\right)$, it performed quite satisfactory during the first sulfidation, yielding a prebreakthrough $\mathrm{H}_{2} \mathrm{~S}$ concentration of approximately 40 to $60 \mathrm{ppmv}$ for nearly 60 hours on-stream. With breakthrough defined as the point at which the outlet concentration of $\mathrm{H}_{2} \mathrm{~S}$ reaches $200 \mathrm{ppmv}$, then breakthrough occurred at approximately 75 hours on-stream. The second sulfidation, however, broke through at 41 hours on-stream and significant quantities of $\mathrm{SO}_{2}$ (usually > $100 \mathrm{ppmv}$ ) were released during the first 30 hours on-stream. This early breakthrough and $\mathrm{SO}_{2}$ release suggests there may have been a problem with regenerability. However, many sorbents do not show stable performance until the third or fourth cycle and, therefore, a multicycle test would be required to establish the extent of regenerability of the sorbent under these conditions.

Figure 3 shows the comparison of series CST1, with an inlet concentration of 2,000 ppmv $\mathrm{H}_{2} \mathrm{~S}$, and series CST4, with 30,000 ppmv $\mathrm{H}_{2} \mathrm{~S}$, conducted with simulated $\mathrm{KRW}$ gas at $871{ }^{\circ} \mathrm{C}$ $\left(1,600{ }^{\circ} \mathrm{F}\right)$. As expected, the higher concentration shows more rapid breakthrough.

The dependence of sorbent performance on the type of simulated coal gas is shown in Figure 4. These experiments were conducted at $538{ }^{\circ} \mathrm{C}\left(1,000{ }^{\circ} \mathrm{F}\right)$ with $30,000 \mathrm{ppmv}_{2} \mathrm{~S}$ inlet concentration. The CST5 series was run with simulated KRW gas, and the CST7 series was run with simulated Shell gas. It is clearly seen that both the efficiency and the capacity of the sorbent are considerably better in the presence of Shell gas. This is in agreement with what had been (1) predicted by the equilibrium calculations of Hepworth and Slimane (1994), and (2) implicated by experiments on the effect of increasing $\mathrm{H}_{2}$ and $\mathrm{CO}$, while decreasing $\mathrm{H}_{2} \mathrm{O}$, by Wakker and Gerritsen (1990). While the sorbent performance in Shell gas, showing a pre-breakthrough concentration of $50 \mathrm{ppmv}$ or less of $\mathrm{H}_{2} \mathrm{~S}$, would be acceptable for most 


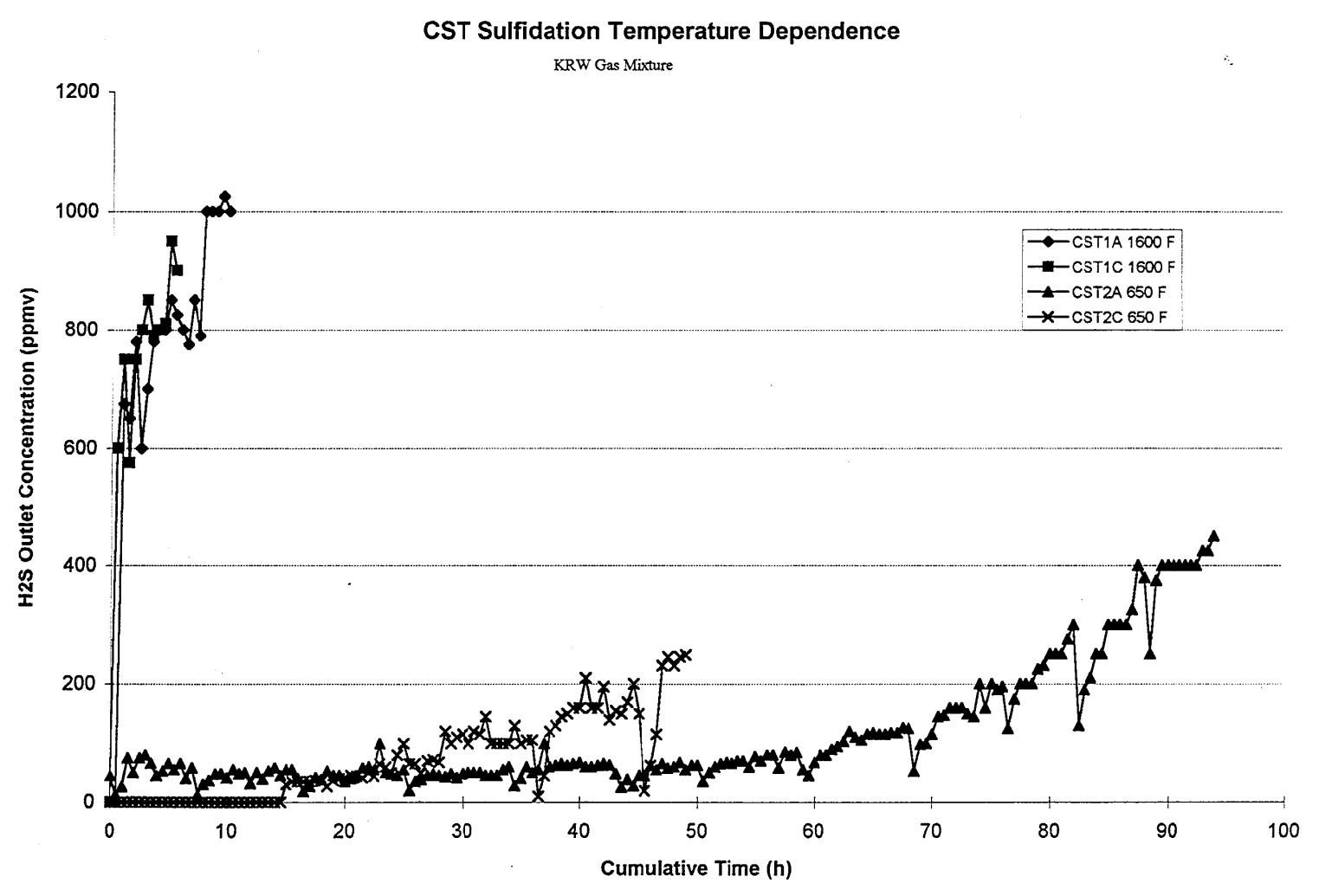

Figure 2

CST Sulfidation Inlet H2S Concentration Dependence KRW Gas Mixture at $1600^{\circ} \mathrm{F}$

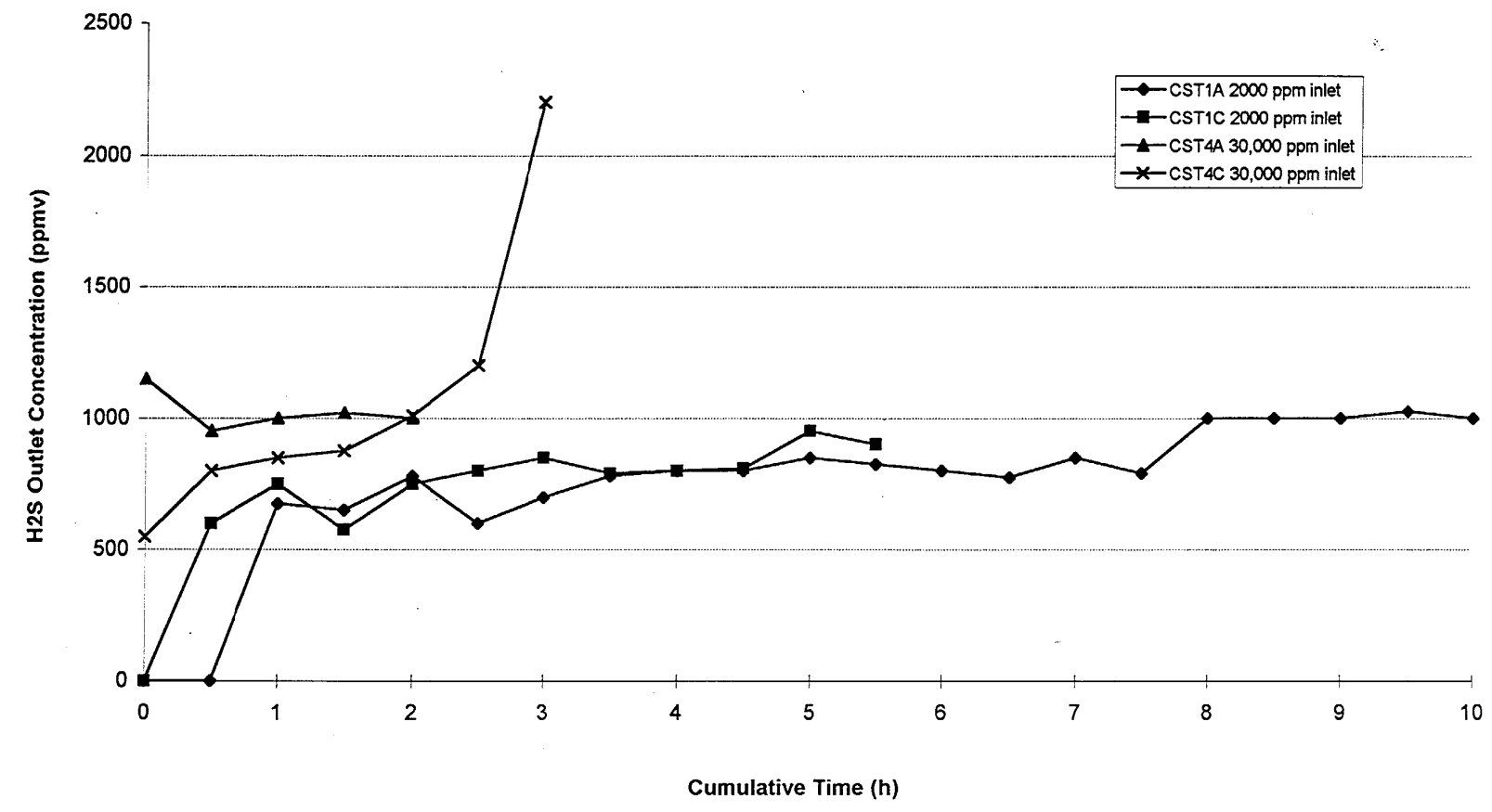

Figure 3 


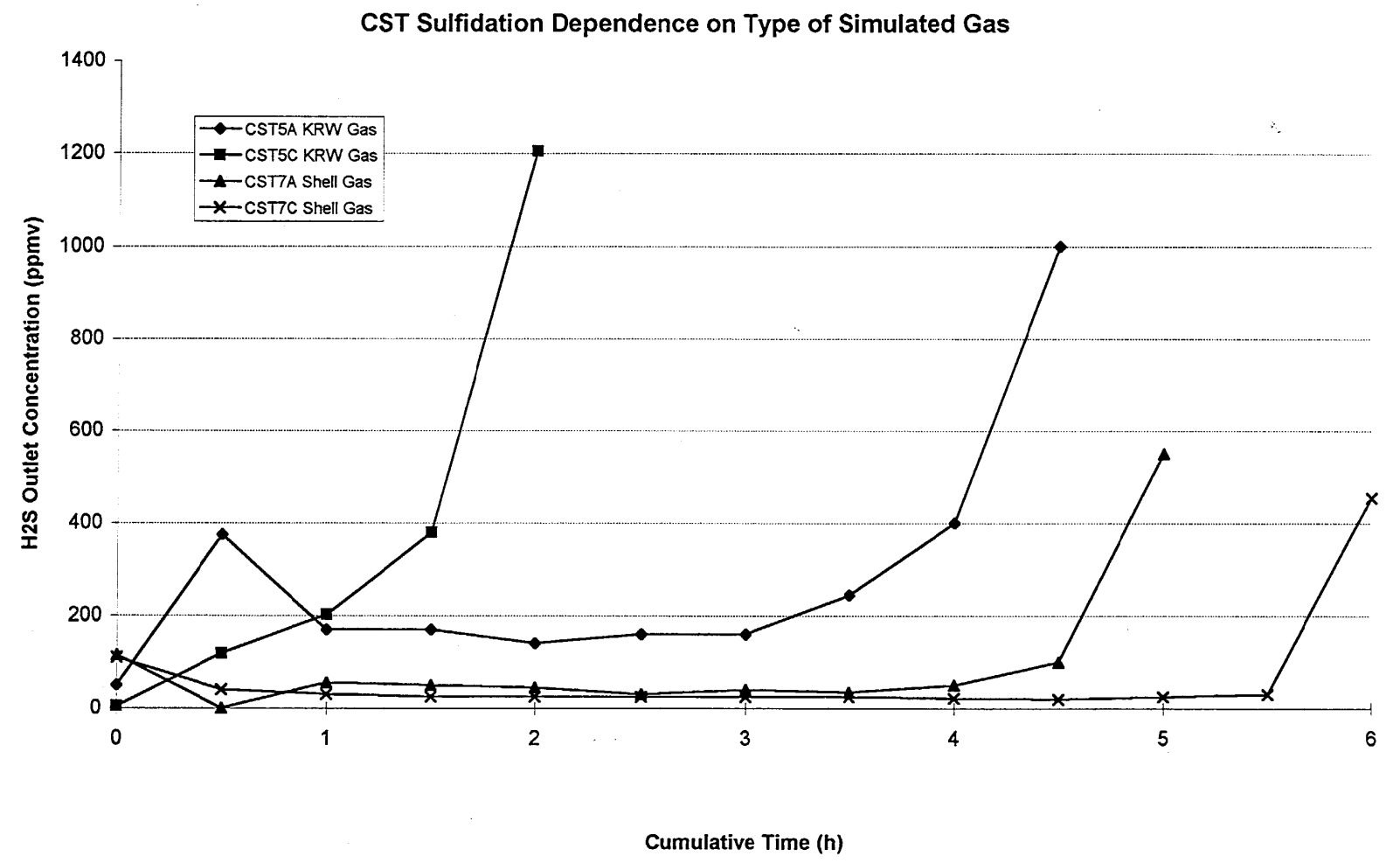

Figure 4

CST Temperature Dependence in Simulated Shell Gas

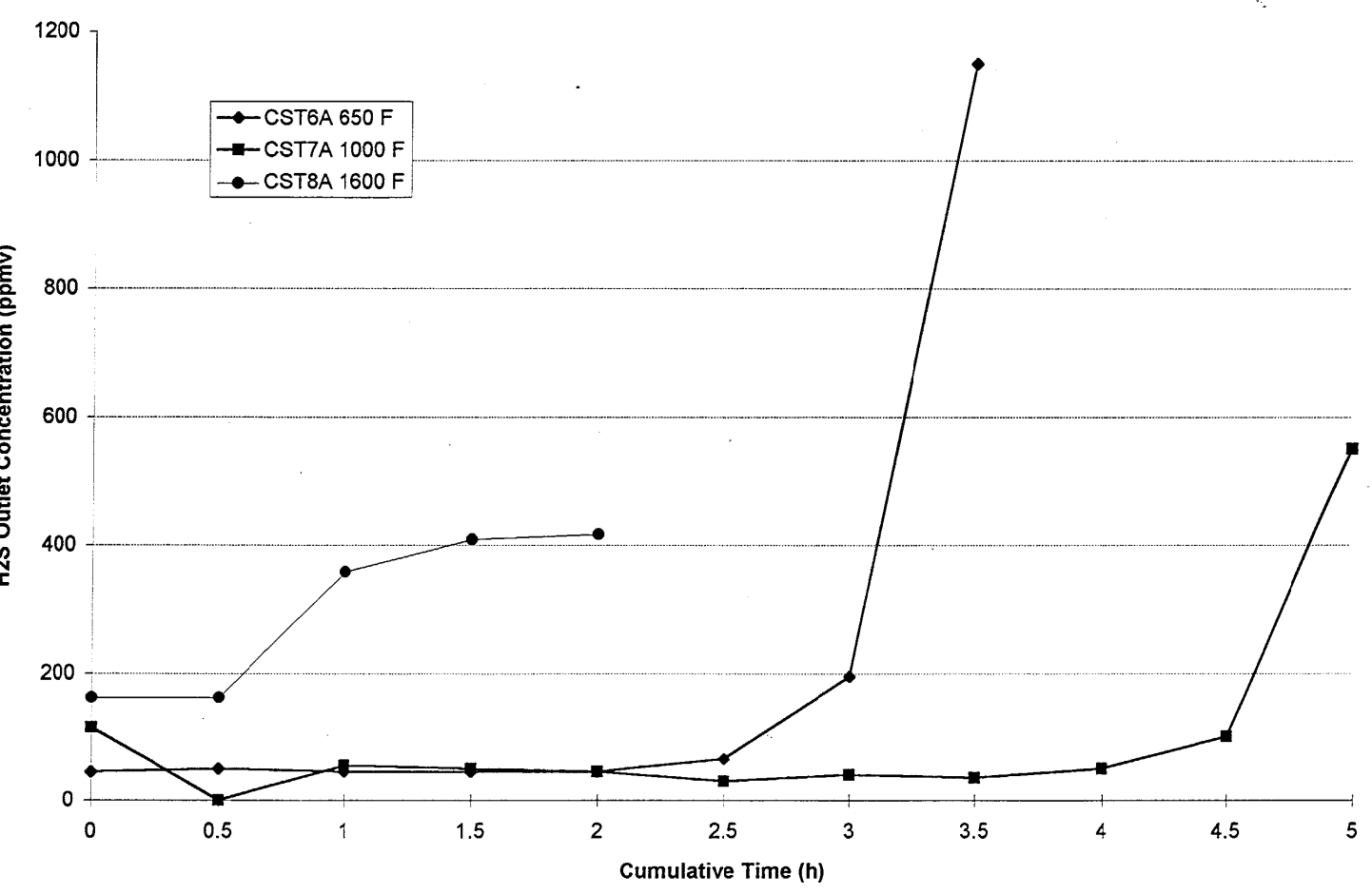

Figure 5 
IGCC applications, the performance in KRW gas, with approximately $180 \mathrm{ppmv} \mathrm{H}_{2} \mathrm{~S}$ in the outlet gas, would be unacceptable.

Figure 5 shows the temperature dependence of sorbent performance in simulated Shell gas during the first sulfidation at 343,538 , and $871{ }^{\circ} \mathrm{C}\left(650,1,000\right.$, and $\left.1,600{ }^{\circ} \mathrm{F}\right)$. All measured concentrations of $\mathrm{H}_{2} \mathrm{~S}$ during the experiment at $871{ }^{\circ} \mathrm{C}\left(1,600{ }^{\circ} \mathrm{F}\right)$ were unacceptably high. However, the sorbent performed quite well at the lower temperatures of 343 and $538{ }^{\circ} \mathrm{C}(650$ and $1,000{ }^{\circ} \mathrm{F}$ ), with pre-breakthrough $\mathrm{H}_{2} \mathrm{~S}$ concentrations of approximately $50 \mathrm{ppmv}$. These data suggest that $538{ }^{\circ} \mathrm{C}\left(1,000{ }^{\circ} \mathrm{F}\right)$ may be the best operating temperature, since the breakthrough time at this temperature was 50 percent longer. Caution should be used in this interpretation, however, because many sorbents do not show their stable performance until the third cycle of sulfidation/regeneration.

Table 4 shows the sulfur loading of each sorbent after being removed from the reactor, through test CST8. The loading was determined by LECO analysis for total sulfur content. Note that the sulfur loadings for CST7 and CST8, which were conducted with simulated Shell gas, were significantly higher than those for CST4 and CST5, which were run with simulated KRW gas under otherwise similar conditions. This is consistent with the related breakthrough curve results.

Table 4. Sorbent Sulfur Loading

\begin{tabular}{|cc|}
\hline Sorbent Type & $\begin{array}{c}\text { Sulfur Loading } \\
(\%)\end{array}$ \\
\hline CST1A-C & 0.76 \\
CST2A-C & 10.75 \\
CST3A-E & 9.39 \\
CST4A-C & 6.76 \\
CST5A-C & 7.02 \\
CST6A-B & 1.78 \\
CST7A-C & 21.27 \\
CST8A-C & 14.85 \\
by Leco analysis & \\
\hline
\end{tabular}

The crush strength (in lb/pellet) for the fresh sorbent and reacted samples through test CST8 are shown in Table 5. The values given are the average from testing 15 pellets, with the standard deviation given in square brackets. It is important to note that in spite of the substantial amounts of sulfur loaded, the crush strength was not significantly less than that of the fresh sorbent, and in many cases was significantly greater. 
Table 5. Crush Strength

\begin{tabular}{|lc|}
\hline \multicolumn{1}{|c}{ Sorbent Type } & $\begin{array}{c}\text { Crush Strength } \\
\text { [std. dev.] }\end{array}$ \\
\hline CST-939 (fresh) & $10.4[3.0]$ \\
CST1A-C & $17.7[7.0]$ \\
CST2A-C & $9.4[5.1]$ \\
CST3A-E & $13.6[6.8]$ \\
CST4A-C & $16.2[7.0]$ \\
CST5A-C & $12.4[4.6]$ \\
CST6A-B & $11.8[5.2]$ \\
CST7A-C & $33.5[10.4]$ \\
CST8A-C & $16.7[7.9]$ \\
\hline
\end{tabular}

\section{Conclusions}

The following conclusions were made from the data collected on the CST-939 sorbent:

- The sorbent efficiency and capacity are much greater at $343{ }^{\circ} \mathrm{C}\left(650{ }^{\circ} \mathrm{F}\right)$ than at $871{ }^{\circ} \mathrm{C}$ $\left(1,600{ }^{\circ} \mathrm{F}\right)$.

- The sorbent efficiency and capacity are much greater in the presence of the more highly-reducing Shell gas than with the less-reducing KRW gas.

- The sorbent showed tremendous capacity for sulfur pickup, with actual loadings as high as 21 weight percent.

- Oxidative regeneration at $871{ }^{\circ} \mathrm{C}\left(1,600{ }^{\circ} \mathrm{F}\right)$ appeared to decompose sulfate; however, unusually high $\mathrm{SO}_{2}$ release during the second sulfidations and/or reductive regenerations indicated incomplete regeneration.

- The average crush strength of the reacted sorbent did not indicate any loss of strength as compared to the fresh sorbent.

- Superior sorbent performance was obtained in the presence of simulated Shell gas at $538{ }^{\circ} \mathrm{C}\left(1,000{ }^{\circ} \mathrm{F}\right)$.

\section{Future Work}

Future work will include a 10-cycle test of the CST-939 sorbent with simulated Shell gas at $538{ }^{\circ} \mathrm{C}\left(1,000{ }^{\circ} \mathrm{F}\right)$ to test for sorbent regenerability and longer term durability. 


\section{References}

Hepworth, M.T. and R.B. Slimane. Hot Coal Gas Desulfurization With Manganese-Based Sorbents. University of Minnesota, DOE/MC/29246-3941, NTIS/DE95000034, 1994.

Turkdogan, E.T. and R.G. Olsson. Desulfurization of Hot Reducing Gases With Manganese Oxide Pellets. Proceedings of the Third International Iron and Steel Congress, American Society for Metals: Chicago, Illinois, April 16-20, 1978, pp. 277-288.

Wakker, J.P. and A.W. Gerritsen. Coal Gasification: Higher Temperature $\mathrm{H}_{2} \mathrm{~S}$ Removal in a Steam Regenerative Process Under Realistic Conditions. American Chemical Society Preprints, 1990a, 35(1), 179.

Wakker, J.P. and A.W. Gerritsen. High Temperature $\mathrm{H}_{2} \mathrm{~S}$ Removal From Process Gases in a Steam Regenerative Process Using $\mathrm{MnO}$ or $\mathrm{FeO}$ on Gamma-Alumina Acceptors. American Chemical Society Preprints, 1990b, 35(1), 170.

Westmoreland, P.R., J.B. Gibson, and D.P. Harrison. Comparative Kinetics of High Temperature Reaction Between $\mathrm{H}_{2} \mathrm{~S}$ and Selected Metal Oxides. Environ. Sci. Technol., 1977, 11, 488.

Westmoreland, P.R. and D.P. Harrison. Evaluation of Candidate Solids for High-Temperature Desulfurization of Low Btu Gases. Environ. Sci. Technol., 1976, 10, 659. 